\title{
Proposed Equation to Estimate the Length of a Hydraulic Jump in a Rectangular Open Channel Hydraulic with Variable Slope, and Its Comparison with Seven Theoretical Equations of Specialized Literature
}

\author{
Martín Mundo-Molina, José Luis Díaz Pérez \\ Engineering Faculty, Chiapas State University, Chiapas, Mexico \\ Email: ic_ingenieros@yahoo.com.mx
}

How to cite this paper: Mundo-Molina, M. and Pérez, J.L.D. (2019) Proposed Equation to Estimate the Length of a Hydraulic Jump in a Rectangular Open Channel Hydraulic with Variable Slope, and Its Comparison with Seven Theoretical Equations of Specialized Literature. Journal of Water Resource and Protection, 11, 1481-1488. https://doi.org/10.4236/jwarp.2019.1112086

Received: October 10, 2019

Accepted: December 8, 2019

Published: December 11, 2019

Copyright $\odot 2019$ by author(s) and Scientific Research Publishing Inc. This work is licensed under the Creative Commons Attribution International License (CC BY 4.0).

http://creativecommons.org/licenses/by/4.0/

\begin{abstract}
A hydraulic jump is a localized phenomenon that generates on an open hydraulic channel; however, its mathematical demonstration is not possible in the turbulent area of the phenomenon, especially in the area where the jump occurs and where its length is measured, so the data must be obtained with direct measurements in a laboratory and through empiric equations. This work presents the results of the generated hydraulic jumps and the measure of its length in a series of tests, where we input different flow rates in a transportable open channel hydraulic with a constant gate opening " $a$ " and a slope of $S=0.0035$, in the Engineering Faculty Research Centre of the Autonomous University of Chiapas. We also present the experimental method to generate a hydraulic jump, the measure of its length and a comparison with seven empirical equations, including the Sieñchi equation used in H-Canales, the most used software for hydraulic channels design in Latin America. The results show that the calculus of $\mathrm{L}$ with the proposed equation has a mean squared error (MSE) of 0.1337, a Bias of -0.0049 , a model efficiency (ME) of 0.9991 and a determination coefficient $\left(R^{2}\right)$ of 0.9993 when compared with the experimental model. Meanwhile, the comparison of $L$ calculated with the Sieñchi equation versus the experimental model resulted in a MSE of 0.1741, a bias of -0.0437 , a ME of 0.9984 and a $R^{2}$ of 0.9997 . Both equations are highly recommended to estimate $L$ in rectangular channels under the conditions presented in this paper, thus, the proposed equation can be applied if $1.2<F_{r_{1}}<5$ y $0.11 \ll \frac{y_{1}}{b} \leq 0.28$. Finally, it must be stated that we also
\end{abstract}


proved that the Pavlosky equation is comparable in precision and accuracy concerning to proposed equation and Sieñchi equation.

\section{Keywords}

Hydraulic Jump, Open Channel Hydraulic, Hydraulics Experiments, Length of the Stilling Basin

\section{Introduction}

The hydraulic jump is a localized phenomenon that occurs in open channels hydraulics $(\mathrm{OCH})$. Giorgio Bidone, an Italian investigator, studied it for the first time in a laboratory in Parella, Turin, during the '40s in the XIX century. He named it intumescence of limited length [1]. The high loss of energy and the turbulence generated in a hydraulic jump can provoke erosion and scouring [2] in an $\mathrm{OCH}$ and great damage to hydraulic structures, so to avoid this issue, the hydraulic jump must be contained in a stilling basin [3] whose length $(L)$ must be calculated correctly to avoid any damage. Whoever, because of the phenomenon's high energy loss and turbulence there is no mathematical equation that can explain or prove what exactly occurs during this intumescence or calculate length with precision, therefore length in a stilling basin is currently calculated with an empiric equation. Then, according to [4] state that: [5]-[13] have been developed various analytical and empirical models from their experimental study for hydraulic jump characteristics, some methods as [7] design of stilling basins or calculate de $L$.

Then, this work presents the results of the generated hydraulic jumps and the measure of its length with the methods: Smetana, Safranez, Einwatcher, Woycicki and Chertusov [14], Pavlovsky and Sieñchi methods.

Contemporary science explains Bidone's intumescence formation with the critical regime theory: a hydraulic jump forms when water flows change from a supercritical to a subcritical regime [15]. The critical regime theory comes from the Bernoulli equation for a constant and incomprehensible flow [16]:

$$
\frac{P}{\rho}+g z+\frac{v^{2}}{2}=C
$$

where $C$ is a constant, $P$ is pressure, $\rho$ is fluid density, $g$ is earth gravity, $z$ is a horizontal comparison plane and $v$ velocity of the water flow.

When Equation (1) is modified and written this way, it is called specific energy [17] [18]:

$$
E=y+\frac{Q^{2}}{2 g A^{2}}
$$

The $y$ variable of Equation (2) is the hydraulic depth, $Q$ is the flow rate, $g$ is earth's gravity and $A$ is the hydraulic area. Giorgio Bidone reported the intumescence phenomenon to the Science Academy of Turin in 1824, that is to say, 
86 years after Daniel Bernoulli published his book about hydrodynamics where he mentions for the first time what we now know as kinetic energy. He named it "vis viva" in Latin (which he took from an original terminology from Leibnitz). During that time there was not a solid theory about total energy or specific energy of water in open channels hydraulics, it developed over time with contributions from Euler, D'Alembert, and Lagrange [1].

On the other hand, the critical regime flow theory only explains the conditions that produce a hydraulic jump, while the hydrostatic laws and momentum law allows us to estimate the conjugate depth, but none of them determines with full mathematical precision the length of a hydraulic jump. Then, many specialized publications or textbooks, for example [14], propose several empirical equations to calculate length in a hydraulic jump, but each one of them is only valid under certain conditions. Table 1 presents seven empirical equations to calculate $L$ and compares them against the estimations made with $\mathrm{H}$-Canales and the results from direct measurements on an experimental prototype.

\section{Materials and Method}

We carried out the experiments in a variable slope open channel hydraulic (VSOCH) which we designed in the Civil Engineering Faculty of the Autonomous University of Chiapas, Mexico. The materials that were used to build the VSOCH (Figure 1) were the following [19] [20]: tubular metal with a rectangular profile (PTR by its acronym in Spanish), $10 \mathrm{~cm}$ wide and $5 \mathrm{~m}$ long, to build the base; hydraulic jack to change the slopes of the VSOCH; acrylic sheets to build the walls and the bottom of the channel; two tripods constructed with three pieces of steels of 3 inches diameter in order to support the weight of the channel; volumetric tank that serves not only as "reference model" for validate $Q$ but also as a deposit "water intake" for the circulation of the flow rate $(Q)$ into the VSOCH; 4 HP gasoline pump with 2 inches diameter of output to drive water from the deposit "water intake" to $\mathrm{VSOCH}$ and to circulate the flow in a closed system.

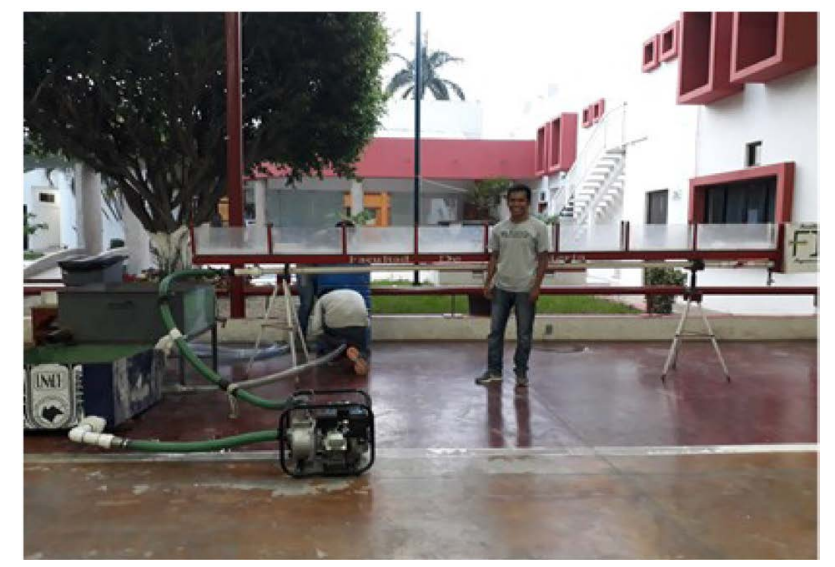

Figure 1. Transportable hydraulic channel (VSOCH) of Engineering Faculty of Chiapas State University, Mexico. 
Table 1. Hydraulic jump length.

\begin{tabular}{lcc}
\hline Name & Equation & Variables \\
\hline Smetana & $L=6\left(y_{2}-y_{1}\right)$ & $y_{2}, y_{1}$, conjugates depth \\
Safranez & $L=5.9 y_{1} F_{\eta_{1}}$ & $y_{1}$, minor conjugate, Froude number \\
Einwatcher & $L=8.3 y_{1}\left(F_{\eta_{1}}-1\right)$ & $y_{1}$, minor conjugate, Froude number \\
Woycicki & $L=\left(y_{2}-y_{1}\right)\left(8-0.5 \frac{y_{2}}{y_{1}}\right)$ & $y_{2}, y_{1}$, conjugates depth \\
Chertusov & $L=10.3 y_{1}\left(F_{r_{1}}-1\right)^{0.81}$ & $y_{1}$, minor conjugate, Froude number \\
Pavlovsky & $L=\left\{2.5\left[1.9\left(\frac{y_{2}}{y_{1}}-1\right)\right]\right\} y_{1}$ & $y_{2}, y_{1}$, conjugates depth \\
Sieñchi & $L=5\left(y_{2}-y_{1}\right)$ & $y_{2}, y_{1}$, conjugates depth \\
\hline
\end{tabular}

Once we installed the VSOCH, we input four different flows rates $(Q)$ through it. Each $Q$ had an arbitrary increase and decrease of $Q$ (Figure 2) in order to avoid statistical tendencies in the $\mathrm{L}$ calculation, while the gate opening " $a$ " remained constant.

We estimated the flow rates $(Q)$ with volumetric method, using the circulation tank of the VSOCH which was previously calibrated. The Manning " $n$ " used is 0.009 (acrylic), and the slope used is $S=0.0035$. Each flow rate generated a hydraulic jump and for each jump; we measured the following variables directly in the experimental model: Length $(L)$, major hydraulic depth $\left(y_{1}\right)$ and minor hydraulic $\left(y_{2}\right)$, which provided the data to calculate Froude's numbers: $F_{\eta_{1}}$ and $F_{r_{2}}$.

Later, we calculated $L$ length with the equations shown in Table 1, and finally we estimated $L$ with the proposed method and $\mathrm{H}$-Canales program which uses the Sieñchi equation. The H-Canales software for channel design is the most used in Mexico and Latin America; in its 3.1.1 version it has a menu with 8 tabs [21]. One of them is named hydraulic jump, which has five options for calculating open channels hydraulics with different geometry: rectangular section, trapezoidal section, rectangular section, parabolic section, and circular section.

\section{Results}

The hydraulic jump that formed from each $Q$ was directly measured in the VSOCH (Figure 3).

The results of $\mathrm{L}$ are shown in Table 2 .

The best method in order to calculate $L$ is the proposed method, because it has the lowest MSE and bias and the upper ME (see Table 3). Table 3 shows the statistical comparisons from the eight methods.

As seen in the results, the proposed method, the Sieñchi method (H-Canales) and the Pavlosky method are the best practices for estimating hydraulic jump 
Table 2. L estimate $(\mathrm{cm})$.

L Real (1) Smetana (2) Safranez (3) Einwatcher (4) Woycicki (5) Chertusov (6) Pavlosky (7) H-Canales (8) Proposed Method (9)

\begin{tabular}{llllllllll}
\hline 28 & 33.48 & 29.65 & 33.41 & 26.28 & 31.82 & 26.51 & 27.90 & 28.40 & 17.64 \\
18 & 21.42 & 25.21 & 23.02 & 22.53 & 25.42 & 16.96 & 17.85 & 10.02 \\
10 & 12.60 & 20.06 & 11.62 & 14.65 & 15.43 & 9.98 & 10.50 & 4.01 \\
\hline
\end{tabular}

Table 3. Statistical comparation between eight methods.

\begin{tabular}{ccccc}
\hline Method & MSE & Bias & ME & R^2 \\
\hline Smetana & 1.7728 & -0.8025 & 0.8859 & 0.9997 \\
Safranez & 4.6130 & -2.0317 & -2.9120 & 0.9933 \\
Einwatcher & 1.8891 & -0.7523 & 0.8857 & 0.9953 \\
Woyciki & 1.7919 & -0.6233 & 0.7777 & 0.9329 \\
Chertusov & 2.5836 & -1.2150 & 0.7074 & 0.9997 \\
Pavlosky & 0.1741 & -0.0437 & 0.9984 & 0.9997 \\
H-Canales & 0.1741 & -0.0437 & 0.9984 & 0.9997 \\
Proposed Method & 0.1337 & -0.0049 & 0.9991 & 0.9993 \\
\hline
\end{tabular}

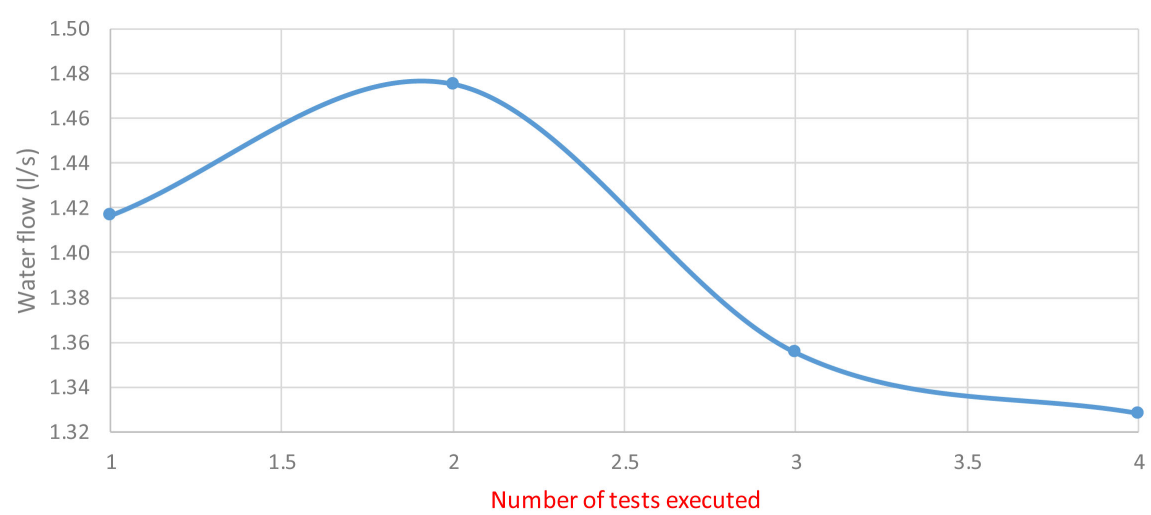

Figure 2. Waterflow (arbitraryincrease and decrease).

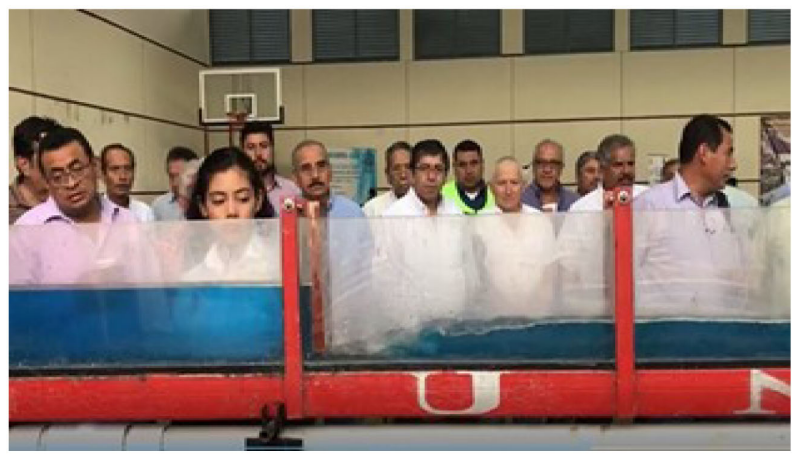

Figure 3. Hidraulic jump under a spillgate.

length under a constant gate opening $a=2 \mathrm{~cm}$, an arbitrary increase and decrease in volume and a slope of $S=0.0035$ (see Figure 4). 


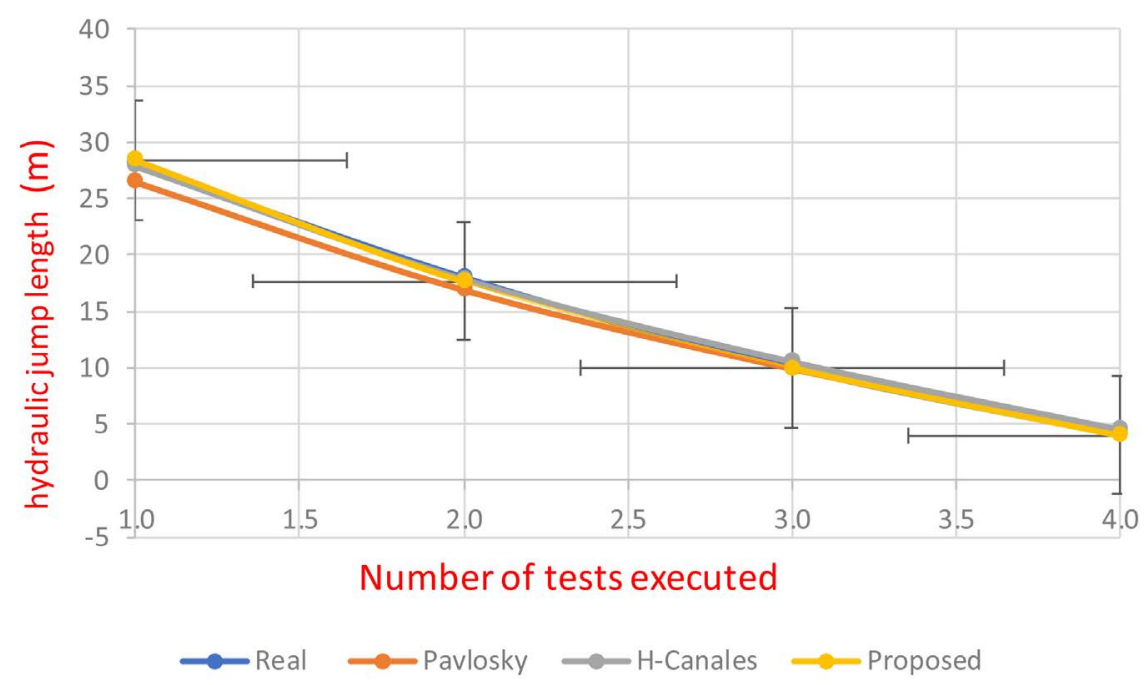

Figure 4. Comparation lenght of hidraulic jump.

The proposed equation in order to calculate $L$ in a rectangular open channel hydraulic shown in Figure 1 is:

$$
L=4.5456\left(y_{2}-y_{1}\right)^{1.0657}
$$

where $L$ is hydraulic jump length in $\mathrm{cm}, y_{2}$ and $y_{1}$ are major and minor hydraulic depth in $\mathrm{cm}$. Whoever, all the empirical equations are formulated under certain limits of operation. The limits of operation of the proposed equation are:

$$
\begin{gathered}
1.2<F_{\eta_{1}}<5 \\
0.11 \ll \frac{y_{1}}{b} \leq 0.28 .
\end{gathered}
$$

\section{Conclusions}

We executed a series of hydraulic experiments in a variable slope open channel hydraulic (VSOCH)from the Engineering Faculty in the Autonomous University of Chiapas, Mexico, with the objective to propose an equation to determine the hydraulic jump length of different water flows with an arbitrary increase and decrease, a constant gate opening " $a$ " and a slope of $S=0.0035$.

We then compared the proposed equation with seven equations presented in specialized literature, including the Sieñchi equation, which is used in the software $\mathrm{H}$-Canales. The results show that the equation proposed in this investigation is exact and precise, and compared with the results of measurements in the experimental model it has an MSE $=0.1337$, bias $=-0.0049, \mathrm{ME}=0.9991$ and $R^{2}=0.9993$. Meanwhile, the calculation of $L$ with the Sieñchi equation, compared with the experimental model, shows and MSE $=0.1741$, bias $=-0.0437$, $\mathrm{ME}=0.9984$ and $R^{2}=0.9997$. The results demonstrate that both equations are highly recommended to estimate $L$ in rectangular open channel hydraulic as shown in Figure 1. The Pavlosky equation is also quite precise, under the experimental conditions presented in this investigation. 


\section{Acknowledgements}

Thank Architect Laura Montserrat Mundo-Navarro for reviewing this paper.

\section{Conflicts of Interest}

The authors declare no conflicts of interest regarding the publication of this paper.

\section{References}

[1] Levi, L.E. (2001) El agua según la ciencia. Asociación Mexicana de Hidráulica. Instituto Mexicano de Tecnología del Agua. Jiutepec, Morelos, México.

[2] Ewah, E.G., Nyah, E.E., Antigha, R.A. and Egbe, J.G. (2018) Experimental Investigation of Energy Dissipation in Hydraulic Jump: A Comparison of Weir and Level Bedded Constricted Flume. International Journal of Engineering Trends and Technology, 61, 6-13.

[3] Youngkyu, K., Gyewoon, C., Hyoseon, P. and Seongjoon, B. (2015) Hydraulic Jump and Energy Dissipation with Sluice Gate. Water, 7, 5115-5133. https://doi.org/10.3390/w7095115

[4] Kumar, G.S., Mehta, R.C. and Dwivedi, V.K. (2013) Modeling of Relative Length and Relative Energy Loss of Free Hydraulic Jump in Horizontal Prismatic Channel. Procedia Engineering, 51, 529-537. https://doi.org/10.1016/j.proeng.2013.01.075

[5] Bélanger, J.B. (1849) Notes sur le cours dhydraulique Notes on a course in hydraulics. Mém. EcoleNat. Ponts et Chaussées, Paris, France, 1849-1850.

[6] Bakhmeteff, B.A. (1932) Hydraulics of Open Channels. McGraw-Hill, New York.

[7] Bradley, J.N. and Peterka, A.J. (1957) The Hydraulic Design of Stilling Basins: Stilling Basin with Sloping Apron (Basin V). Journal of the Hydraulics Division, 83, $1-32$.

[8] Chow, V.T. (1959) Open-Channel Hydraulics. McGraw-Hill, New York.

[9] Henderson, F.M. (1966) Open Channel Flow. MacMillan, New York.

[10] Herbrand, K. (1973) The Spatial Hydraulic Jump. Journal of Hydraulic Research, 11, 205-218. https://doi.org/10.1080/00221687309499774

[11] Bhutto, H.B.G. (1987) Hydraulic Jump Control and Energy Dissipation. PhD Thesis, Mehran University of Engineering \& Technology, Jamshoro.

[12] Hager, W.H. (1992) Energy Dissipators \& Hydraulic Jumps. Kluwer Academic Publication, Dordrecht, The Netherlands, 151-173. https://doi.org/10.1007/978-94-015-8048-9

[13] Rajaratnam, N. and MacDougall, R.K. (1983) Erosion by Plane Wall Jets with Minimum Tail Water. Journal of Hydraulic Engineering, 109, 1061-1064. https://doi.org/10.1061/(ASCE)0733-9429(1983)109:7(1061)

[14] Gardea, V.H. (1999) Hidráulica de canales. Facultad de Ingeniería, UNAM. México, D.F.

[15] Sotelo, A.G. (2002) Hidráulica de canales. Facultad de Ingeniería de la Universidad Nacional Autónoma de México. Ciudad de México, México.

[16] Chanson, H. (2006) Minimum Specific Energy and Critical Flow Conditions in Open Channels. Journal of Irrigation and Drainage Engineering, 132, 498-502. https://doi.org/10.1061/(ASCE)0733-9437(2006)132:5(498) 
[17] Chow, V.T. (2004) Hidráulica de canales abiertos. McGraw-Hill, Bogotá, Colombia.

[18] Vatankhah, R.A. and Valiani, A. (2011) Analytical Inversion of Specific Energy Depth Relationship in Channels with Parabolic Cross Sections. Journal des Sciences Hydrologiques, 56, 834-840. https://doi.org/10.1080/02626667.2011.583250

[19] Mundo, M.M. (2014) Diseño y construcción de una canal económico en el laboratorio de hidráulica de la Facultad de Ingeniería de la UNACH. Congreso Latinoamericano de Hidráulica, Santiago de Chile.

[20] Mundo, M.M. (2018) Volumetric Measuring of Sediment in a Transportable Prismatic Channel. Revista Internacional de contaminación Ambiental, 34, 173-176.

[21] Villón, B.M. (2016) H-Canales 3.1. Manual de usuario. Lima, Perú. 